УДК 94 (47). 084.9

DOI 10.18413/2687-0967-2020-47-2-378-386

\title{
ОСОБЕННОСТИ ИДЕОЛОГИЧЕСКОЙ ПОЗИЦИИ «АРХИТЕКТОРА ПЕРЕСТРОЙКИ», ПЕРВОГО ЗАМЕСТИТЕЛЯ ЗАВЕДУЮЩЕГО ОТДЕЛОМ ПРОПАГАНДЫ ЦК КПСС А.Н. ЯКОВЛЕВА В 1960-1970-е ГОДЫ
}

\author{
FEATURES OF THE IDEOLOGICAL POSITION OF THE «ARCHITECT OF \\ PERESTROIKA», FIRST DEPUTY HEAD OF THE PROPAGANDA DEPARTMENT \\ OF THE CPSU CENTRAL COMMITTEE A.N. YAKOVLEV IN THE 1960s AND 1970s
}

\author{
А.Н. Сивов \\ A.N. Sivov \\ Московский педагогический государственный университет, \\ Россия, Москва, 115571, Проспект Вернадского, 88 \\ Moscow state pedagogical University, \\ 88 Vernadsky Avenue, 115571, Moscow, Russia \\ E-mail: sivov.tolya@mail.ru
}

\begin{abstract}
Аннотация
Статья посвящена изучению особенностей идеологической работы секретаря ЦК КПСС Александра Николаевича Яковлева в период 1960-1970-х годов, во время, предшествующее политике «перестройки» в СССР. Данные проблемы представляются малоизученными. Рассматриваются его суждения по совершенствованию идеологической работы, пропаганды, улучшению ее содержания и методологии. Приведены сведения из архивных источников, которые свидетельствуют о стремлении А.Н. Яковлева объективно показать значение личности и политической деятельности И.В. Сталина. Дана сравнительная характеристика исторической роли В.И. Ленина и И.В. Сталина в понимании А.Н. Яковлева. Сделан вывод о серьезном влиянии А.Н. Яковлева на формирование конкретных идеологических оценок в 1960-1970-е годы, хотя при этом его влияние на советскую идеологию в целом не стоит преувеличивать. Отмечается, что формирование в партийно-пропагандистском аппарате идеологических установок, типичных для периода «перестройки», происходило задолго до ее официального объявления руководством КПСС.
\end{abstract}

\begin{abstract}
The Article examines the characteristics of the ideology Secretary of the CPSU Central Committee Alexander N. Yakovlev in the period 1960-1970s, during the preceding policy of «perestroika» in the USSR. These problems appear to be poorly understood. His opinions on improving ideological work, propaganda, improving its content and methodology are considered. The article presents information from archival sources that indicate the desire of A.N. Yakovlev to objectively show the significance of the personality and political activity of I.V. Stalin. A comparative characteristic of the historical role of V.I. Lenin and I.V. Stalin in the understanding of A.N. Yakovlev is given. The conclusion is made about the serious influence of A.N. Yakovlev on the formation of specific ideological assessments in the 1960s and 1970s, although, at the same time, his influence on Soviet ideology as a whole should not be exaggerated. It is noted that the formation in the party propaganda apparatus of ideological attitudes typical of the period of «perestroika» occurred long before its official announcement by the leadership of the CPSU.
\end{abstract}

Ключевые слова: А.Н. Яковлев, идеологическая работа, пропаганда, И.В. Сталин, В.И. Ленин, Центральный Комитет Коммунистической партии Советского Союза.

Keywords: A.N. Yakovlev, ideological work, propaganda, I.V. Stalin, V.I. Lenin, Central Committee of the Communist party of the Soviet Union. 
Изучение периода «перестройки» в СССР и распада советского государства требует тщательного и объективного подхода к оценке суждений того или иного политического деятеля. Несмотря на большой объем литературы, посвященной данному периоду, исследований, характеризующих отдельных политков, немного. Малоизученной представляется также и тема формирования предпосылок конкретных идеологических постулатов, проявившихся во второй половине 1980-х годов. Между тем их появление было отнюдь не случайным, а в общем закономерным результатом эволюции предшествующих общественных запросов и ожиданий. Но нельзя не учитывать и роли партийнопропагандистского аппарата, степени его готовности к пониманию новых тенденций в формальной и неформальной идеологических сферах.

Одним из влиятельных политиков того времени был Александр Николаевич Яковлев. В его компетенции находились вопросы идеологии, наиболее важные в условиях происходивших в Советском Союзе перемен в период «перестройки». Следует отметить, что многие из идеологических тезисов, прозвучавших во второй половине 1980-х годов, восходят в своем содержании к 1960-1970-м годам.

Историография, посвященная непосредственно жизни и деятельности А.Н. Яковлева, невелика. Здесь отличается зарубежная историография, в которой следует отметить монографию Р. Пайпса [Pipes, 2015]. Но прямо или косвенно его биографии в период 1980-х годов касаются очень многие авторы. При этом оценочные суждения даются в основном негативного порядка, характеризующие Яковлева в качестве «агента влияния» иностранных государств [Крючков, 2003; Широнин, 2016; Бобков, 2011]. Согласно этой версии, Яковлев с самого начала «перестройки» был готов к целенаправленной дискредитации советской идеологии и лишь выжидал, чтобы наиболее эффективно произвести подмену устоявшихся идеологических ценностей и понятий.

Значительное влияние Яковлева на формирование советской идеологии в целом выделяет в своих воспоминаниях Е.К. Лигачев, называя его «серым кардиналом» [Лигачев, 2011]. А.Н. Яковлев оказался даже персонажем исторической прозы [Минутко, 2010]. Многие аспекты идеологического обоснования происходивших в стране перемен изучались А.С. Барсенковым [Барсенков, 2001]. Интересны оценки идеологических разногласий, в частности, на уровне противостояния центра и регионов, даваемые в монографии А.В. Шубина [Шубин, 2001]. О необходимости перемен в официальной идеологии в условиях низкого доверия со стороны общества к партийно-политической системе управления писал Р.А. Медведев [Медведев, 2010].

Можно отметить также статьи в рецензируемых журналах, авторы которых в той или иной степени затрагивали проблемы идеологических трансформаций советской политической системы в 1980-е годы [Вилков, Пивоваров, 2016; Артемов, 2017; Логвенков, 2017; Казьмина, Казьмин, 2017]. Следует отметить исследования форм и методов идеологической работы в СССР [Цветков, 2016, 2017]. Поможет в этом и обращение к историческим источникам, не вводившимся ранее в широкий научный оборот. Среди них большое значение имеет документальный двухтомник «Александр Яковлев» (редактор и составитель - его сын А.А. Яковлев), включающий немало исторических свидетельств, отражающих его политическую биографию [Александр Яковлев, 2008]. Тем не менее и здесь приоритет отдается периоду «перестройки» и 1990-х годов. Предшествующие годы идеологической работы Яковлева в них практически не отражены. Таким образом, его деятельность в 1960-1970-е годы заслуживает дополнительного изучения.

Неправомерно, очевидно, искать объяснение эволюции его мировоззрения исключительно в субъективном восприятии Яковлевым идеологических программных установок к карьеристским соображениям. Важнее представить себе степень вляиния на него конкретных перемен в общественно-политической жизни страны не только в середине 1980-х, но и в более раннее время.

Целесообразно поэтому ознакомиться с некоторыми аспектами работы Александра Николаевича в Отделе пропаганды ЦК КПСС. Деятельность его начиная с 1960-х годов 
можно было бы охарактеризовать как период, когда он уже являлся не безоговорочным приверженцем принципов официальной идейно-политической работы, а становился сторонником перемен, многие из которых будут реализованы во второй половине 1980-х. Документы, отражающие эти перемены, сосредоточены в его личном фонде, переданном в Государственный архив Российской Федерации (ГА РФ).

Еще в начале 1964 года, занимая должность заведующего сектором газет в Отделе пропаганды ЦК КПСС, Яковлев решительно выступал за активизацию органов печати, радио, телевидения и кино, оценивая их как важнейшие инструменты идеологического воздействия на население СССР. Для него приоритетными становятся не методы «железного занавеса», связанные с решительным запретом «иновещания», а противодействие («контрпропаганда») Западу посредством создания более эффективной «системы ценностей», поддерживаемой советским населением: «...приняты и принимаются меры по более рациональному использованию средств радиовещания, включая прекращение глушения официальных радиостанций капиталистических стран, что позволило направить освободившиеся мощности непосредственно на радиовещание и потребовало бы большой контрпропагандистской гибкости с нашей стороны...» [Яковлев, Активизировать печать... Л. 2]. Как известно, уже в годы «перестройки» инициативы о прекращении «глушения» этих радиостанций были воплощены в жизнь. Примечательно, что многие сотрудники КГБ СССР и специалисты по информационно-психологическому противостоянию отмчали негативные последствия разрешения радиовещания возможных идеологических противников [Волкогонов, 1983].

Немало внимания Александр Николаевич уделял противодействию националистическим взглядам. По его мнению, национализм был наиболее опасен для стабильности государства и общества. И позднее, во второй половине 1980-х годов, Яковлев постоянно подчеркивал эту опасность, видя в ней едва ли не главную причину распада Советского Союза. Особое значение это имело для региональной прессы, в которой под видом сохранения «национальных культурных традиций» мог пропагандироваться «национализм». В одном из документов он отмечал: «...Правда, кое-где иные хранители так называемых "национальных“ традиций пытаются протиснуться в печать, отравить сознание советских людей. В прошлом году были подвергнуты острой критике некоторые писатели Каракалпакии, которые обнародовали вредные в идейном отношении произведения, освещающие явления нашей общественной жизни с узких, эгоистических позиций. Назовем хотя бы статью А. Алламуратова «Несколько слов о каракалпакской музыке». Под видом защиты народных музыкальных мелодий автор статьи идеализирует прошлое каракалпакского народа, выражает недовольство тем, что творческие коллективы много внимания уделяют разучиванию, исполнению музыкальных произведений народов СССР. Мы не должны проходить мимо явлений, когда нашу печать используют для проповеди националистических взглядов» [Активизировать печать..., Л. 5].

Обличение проявлений национализма в советских республиках означало для Яковлева отнюдь не критику политических достижений страны «развитого социализма», но призвано было сохранить «интернациональное единство», что позднее, в 1980-е годы, стало резко контрастировать с очевидной нерешенностью многих проблем в СССР, в том числе и проблем национальной политики.

При оценке конкретной методологии пропагандистской работы Яковлев обращал внимание на актуальность наполнения газет качественным, интересным материалом. По его мнению, не должно быть каких бы то ни было исторических фальсификаций, наличие которых способно было резко снизить степень доверия к средствам массовой информации. Вот как писал он об одном инциденте с публикацией газетой недостоверных сведений: «...Недавно газета «Гудок» в двух номерах опубликовала воспоминания В. Гурченко «Солдаты в гражданском». В этих воспоминаниях Гурченко совершенно бездоказательно выдает себя за члена штаба подпольной группы сопротивления «Искра», действовавшей якобы в Германии в 1942-1945 гг. Если верить автору, то членам группы сопротивления 
все удавалось легко и просто: снимать на железных дорогах рельсы и пускать поезда под откос, поджигать скирды хлеба, обрывать электрокабели, ломать прокатные станы, токарные станки и компрессоры, распространять листовки и даже выпускать стенную газету. В целях личной славы Гурченко в течение вот уже многих лет добивается признания его «заслуг» перед Родиной. При этом он грубо подтасовывает факты, вооружается липовыми документами, подыскивает фиктивных свидетелей. Проверка, однако, показала, что антифашисткой группы сопротивления «Искра» просто не существовало. Не подтверждают фактов существования группы «Искра» и ее подпольной деятельности и сами немецкие товарищи, которых Гурченко назвал в качестве очевидцев и свидетелей событий. Воспоминания Гурченко проникли на страницы газеты «Гудок» в результате грубого нарушения установленного порядка проверки и подготовки материалов перед их опубликованием. В погоне за сенсацией редакция газеты допустила грубую ошибку...» [Активизировать печать..., Лл. 6, 7].

В данной ситуации Яковлев проявил не только принципиальность и твердость в отношении к фальсификаторам истории, но и тщательность в историческом расследовании. Надо заметить, что и позднее, в период «перестройки», он неоднократно будет обращать внимание на достоверность тех или иных исторических свидетельств.

Примечательно, что Яковлев немало критиковал и редакционную политику региональных изданий, их стремление к публикации непроверенных, «жареных» фактов. Это также наносило сильный ущерб по репутации изданий. «...Иной раз создается впечатление, - писал он, - что вместо гневного обличения авторы злорадствуют по поводу уродливых фактов. Например, редакция газеты «Комсомолец Киргизии» специальный выпуск «Комсомольский прожектор» превратила в витрину недостатков. Потеряв чувство меры в критических материалах, работники редакции явно и преднамеренно сгущают краски. В течение нескольких месяцев в газете мелькала рубрика «Тревога! Тревога! Тревога!» Уже одни заголовки, уместные разве только в уголовной хронике, показывают уровень материалов: «Преступление в Кара-Су», «Километры расточительства», «Миллионы на свалке» и многие другие. Причем чуть ли не в каждой корреспонденции настойчиво подчеркивалось: «Наши корреспонденты побывали на месте преступления». В этой же газете введена рубрика «Трибунал чести». Забыв о том, что такое название ко многому обязывает, кригизкие (орфография А.Н. Яковлева сохранена - авт.) журналисты заботятся только об одном, им хочется написать похлеще, ошарашить читателя...» [Активизировать печать..., Л. 7].

Представляется важным отметить, что Александр Николаевич уже в то время понимал особенности деятельности некоторых работников советских СМИ, которые могли бы дестабилизировать общественные настроения: «...Следует подчеркнуть, что писатели и работники искусства поняли ошибки и стремятся доказать это своим творчеством. Разумеется, было бы наивным думать, что все сделано и все вопросы решены. Мы далеки от такой маниловщины в оценке положения в области литературы и искусства. Неверные тенденции еще не преодолены до конца, а с рецидивами их мы встречаемся и в произведениях искусства, и в художественной критике...» [Активизировать печать..., Л. 35].

Но наиболее показательным из «доперестречных» представлений Яковлева является его оценка личности и политики И.В. Сталина, в частности, в сравнении с В.И. Лениным. Им были написаны тезисы, посвященные 90-летию со дня рождения Сталина (1969 год).

Примечательно, что многие из тех оценок, которые главный «идеолог перестройки» давал Сталину и его юбилею, позднее будут повторяться в его новых публикациях. Следует отметить, что для формирования подобных взглядов немаловажное значение имело отношение к личности и к политической позиции И.В. Сталина. Несмотря на процессы «оттепели» и начавшуюся «десталинизацию» после XX и особенно XXII съездов КПСС, отношение к бывшему правителю в советском обществе оставалось неоднозначным. Немало было тех, кто считал, что политика Сталина и его деятельность во главе Советского государства были правильными. Яковлеву в этой связи представлялось необхо- 
димым более четко обозначить приоритеты идеологической платформы ЦК КПСС, к чему обязывал и его официальный статус первого заместителя заведующего Отделом пропаганды ЦК КПСС, одной из важнейших политических структур в СССР.

И ранее Яковлев, как уже отмечалось выше, находясь на своем посту, поднимал различные вопросы о формах и методах проводимой идеологической работы. В специально составленной им служебной записке о «юбилее Сталина» Яковлев отмечал принципиальную важность юбилейных дат в Советском Союзе и приводил тезис о значении наступающего 90-летия со дня рождения Сталина. При этом указывалось и на целенаправленные усилия США по «дезорганизации» советского общества и «единства коммунистов и беспартийных» [Предложения А.Н. Яковлева..., Л. 1]. Он проводил примечательный сравнительный анализ между известными ему общественными представлениями о Сталине, отмечая при этом, что составить объективно-научную картину представляется невозможным без специальных исследований. Он перечислял заслуживающие внимания оценки бывшего правителя СССР. Значимым аспектом общественного представления о Сталине и «сталинизме», по мнению Яковлева, были следующие:

«...Сталин был верный ленинец. Всю политику партии он строил в соответствии с учением Маркса, Энгельса, Ленина, считал себя их учеником, относился к ним с огромным уважением. В течение 30 лет своего руководства он добился величайших успехов, превратил нищую и забитую страну в одну из самых великих держав современности. Эти его заслуги никогда не будут забыты.

- Сталин был носителем сильной власти. Сильная власть - первый признак государства, совершенно необходима для осуществления любого политического курса.

- Сталин выиграл войну, без него мы ее проиграли бы.

- Сталин ежегодно снижал цены, а это важнейшее свидетельство его постоянной заботы о народе.

- Сталин очень высоко ценил и поддерживал престиж нашего государства, не гнул спину перед Западом, вел себя перед иностранными деятелями, даже с такими китами как Черчелль (орфография источника) и Рузвельт, с огромным достоинством.

- Сталин был скромен, пренебрегал личными интересами, не вызволил из плена родного сына в обмен на фельдмаршала.

- Сталин был беспощаден к жулью, проходимцам, хапугам, ко всем, кто пытается греть руки на народном добре - обогащаться, обзаводиться дачками, участками, машинами и т. п.

- Сталин берег копейку, не держал на нашей шее иностранных нахлебников.

- При Сталине не было разброда в международном коммунистическом движении. Все нас благодарили и почитали. Единственная страна, которую он отверг, была Югославия, и в этом, как показали события, он был совершенно прав.

- При Сталине был порядок - дисциплина труда; жестоко каралось посягательство на общественную собственность, указания сверху строго соблюдались и т. п. Сейчас порядка не стало.

- При Сталине на низовом звене была критика и самокритика. Начальство боялось зажимать критику, его можно было критиковать. Сейчас критика исчезла.

- При Сталине у руководителей на местах не было столь широкой власти, боялись ЦК, в ЦК тогда можно было найти правду. Сейчас - иное дело. ЦК уже не боятся, роль личных взаимоотношений возросла, возможность несправедливо поступить с человеком усилилась, нет, как в прошлом, гарантий от произвола начальства.

- При Сталине у руководства было высоко развито чувство ответственности, безответственность строго каралась. Сейчас безответственность возросла. Многие умудряются ничего не делать, ничего не решать, не брать на себя ответственности, и все сходит с рук. 
- При Сталине в теоретическом освещении практики социализма все было ясно, четко и понятно. Неясных вопросов не было. Сам развивал теорию...» [Предложения А.Н. Яковлева..., Л. 3].

Таким образом, в изложенных Яковлевым положениях, отражающих как бы «перечень» преобладающих в обществе мнений в отношении Сталина, вполне очевидно присутствует и особо выделенное противопоставление современного (1960-е годы) состояния и периода «правления» Сталина. Предлагается также своеобразный контраст представлений о И.В. Сталине и Л.И. Брежневе в «народном сознании». И сравнение здесь оказывается не в пользу тогдашнего Генерального Секретаря. Возможно, зная свойственные Леониду Ильичу и его окружению честолюбивые стремления, Яковлев рассчитывал добиться дополнительного эффекта. Очевидно и то, что проводил параллели между Владимиром Ильичом и Леонидом Ильичом, стремясь явно польстить последнему. Для аппаратной работы это был вполне оправданный прием.

Далее в записке перечислялись общественные мнения и представления против Сталина и «сталинизма». По своему объему они занимали на 2 листа больше положительных. Яковлевым фиксировалось следующие: «...Сталин ослабил партию, армию и страну массовыми необоснованными репрессиями. Гитлер уничтожил одного своего соратника. Сталин физически истребил всех соратников В.И. Ленина, с которыми В.И. Ленин вел партию к победе 1917 года, победил в гражданской войне и приступил к строительству социализма.

Сталин замахнулся на святая святых в партии, на ее высший руководящий орган съезд партии, физически истребив большую часть делегатов XVII съезда.

Сталин расстрелял мозг партии - ее Центральный комитет, уничтожив почти весь ЦК, избранный XVII съездом. То же самое по вине Сталина произошло с руководящим ядром в каждом районе страны, в каждой области и республике.

Не Сталин выиграл войну. Если бы его вообще не существовало, ЦК в лице соратников В.И. Ленина лучше бы подготовили партию и страну к войне. Сталин проморгал начало войны. Если бы в ЦК была здравая атмосфера, этого не произошло бы.

Незадолго до войны Сталин обезглавил армию, уничтожив почти весь ее высший командный состав. Тот урон, который нанес Сталин по комсоставу, значительно больший, чем когда-либо в истории испытывала какая бы то ни было армия, понесшая самое сокрушительное поражение от врага.

Сталин поставил органы безопасности над партией. В следственных органах и местах заключения создал режим пыток. Условия царской тюрьмы, где томили революционеров, были значительно человечней, хотя царь боролся со своими врагами, а Сталин бил по своим, по революционерам.

Массовыми репрессиями Сталин опорочил социализм, опозорил имя русского революционера-ленинца, ибо все свои деяния прикрывал святым именем В.И. Ленина. Его ближайшим соратником был откровенный мерзавец - Берия и его шайка.

Сталин был самый нескромный человек, превратив себя при жизни в божество, позволяя в его присутствии так бесстыдно возвеличивать себя - не все короли этого допускали.

Сталин был величайший фарисей и лицемер. В момент наивысшего нарушения законности он больше всего говорил о демократии. В условиях массового истребления людей он заявил, что из всех капиталов, которыми располагает партия, самый ценный, это люди.

Неисчерпаемое богатство диалектики он свел к отдельным пунктам и цитатам, убив тем самым живую душу марксизма. Все, что ему приписывалось (как вклад в теорию), было сделано В.И. Лениным. Он не развил, а омертвил теорию...» [Предложения А.Н. Яковлева..., Лл. 3, 4, 5].

В отрицательных мнениях, перечисленных Яковлевым, присутствовало немало обвинений, которые в период гласности будут широко распространяться во многих советских «масс-медиа». Очевидно также, что проблемы идейно-политической работы в СССР 
конца 1960-х годов он косвенно связывал с ее упадком при Сталине. Можно заметить и упомянутое в записке сравнение Сталина с Гитлером, что представляло собой весьма распространенное явление в англо-американской политологии и публицистике середины $\mathrm{XX}$ столетия.

Говоря о значении личности И.В. Сталина, Яковлев считал необходимым ссылаться на авторитет В.И. Ленина, что в целом было характерно для агитационнопропагандистских установок 1960-х - начала 1970-х годов. «...С моей точки зрения, - писал Яковлев, - в связи с 90-летием Сталина "Правда“ могла бы опубликовать статью, но не 21 декабря, а на один-два дня раньше. Статья, на мой взгляд, не должна быть посвящена Сталину, но в своей большей части она скажет о нем. К примеру, статья могла бы называться (условно) «В.И. Ленин об облике пролетарского революционера». В рамках ленинской тематики нашей пропаганды статья на эту тему была бы вполне уместной. В ней излагались бы ленинские взгляды о вождях пролетариата Марксе, Энгельсе, Сталине, Свердлове. Здесь же говорилось бы о самом В.И. Ленине как идеале вождя. Оценка же Сталина должна базироваться на постановлении ЦК КПСС «О преодолении культа личности и его последствий» [Предложения А.Н. Яковлева..., Л. 7].

Таким образом, будущий «архитектор Перестройки», как его позже назовут, в конце 1960-х - начале 1970-х годов выступал с позиций сохранения и дальнейшего развития идеологических установок периода «оттепели». Особенно ярко это проявилось в отношении оценки роли личности И.В. Сталина в истории Советского Союза. Яковлев продолжал считать актуальными принципы партийной коллегиальности, борьбы с «последствиями культа личности», провозглашенные на XX съезде КПСС. Негативно оценивал Яковлев проявления экстремизма, причем в любой форме, какими бы привлекательными (например, борьба за исключительность традиций «национальной культуры») целями и лозунгами он ни прикрывался. По его мнению, развитие любых экстремистских взглядов может привести к дестабилизации положения в стране, к серьезным общественно-политическим конфликтам. Сохраняли свою неизменную значимость для Александра Николаевича и задачи совершенствования методики идеологической работы. При этом особое внимание он уделял актуализации и доступности ее для массового слушателя и читателя. В то же время нельзя не отметить наличие схематизма в отстаиваемых им подходах к принципам организации пропаганды и агитации. Очевидно, имело место и сугубо субъективное отношение Яковлева к аппаратным конфигурациям работы, переоценка их значимости как для партийной организации, так и для взаимодействия с населением. Специфические особенности периода 1960-1970-х годов нашли отражение и в последующих формах видения им специфической идеологии периода «перестройки».

\section{Список литературы}

1. Артемов А.В. 2017. Идеология обновления в риторике М.С. Горбачева как базовый элемент образа перестройки (на примере подготовки выступления на февральском Пленуме ЦК КПСС 1988 г.). Вестник Пермского университета. Серия: История. Выпуск 2 (37): 106-114. МГУ, 276

2. Барсенков А.С. 2001. Реформы Горбачева и судьба союзного государства 1985-1991. М.,

3. Бобков Ф.Д. 2011. Как готовили предателей. Начальник политической контрразведки свидетельствует. М., Эксмо, 240.

4. Вилков А.А., Пивоваров В.А. 2016. Пропагандистский фактор дезориентации и раскола советского общества и распада СССР. Известия Саратовского университета. Серия: Социология, политология. 2016. Том 16, выпуск 4. 432-438.

5. Волкогонов Д.А. 1983. Психологическая война: Подрывные действия в области общественного сознания. М., Воениздат, 283.

6. Казьмина М.В. Казьмин В.Н. 2017. Отечественная историография 1970-х годов - начала XXI века об идейно-политической жизни России 1971-1991 годов. Вестник Кемеровского государственного университета. № 2: 50-57.

7. Крючков В.А. 2003. Личное дело. М., Эксмо, 480. 
8. Лигачев Е.К. 2011. Кто предал СССР? М., Алгоритм-Эксмо, 285.

9. Логвенков И.С. 2017. Демонтаж СССР: историография причин, условий и факторов, Вестник Московского университета. Серия 21. Управление (государство и общество), № 4: 129-145.

10. Медведев Р.А. 2010. Советский Союз. Последние годы жизни. М., АСТ, 637.

11. Минутко И.А. 2010. Провидец. М., Независимое издательство «ПИК», Российская политическая энциклопедия, 560.

12. Цветков В.Ж. 2016. Актуальность опыта идеологической работы в период подготовки и начала «перестройки» в СССР: нереализованные возможности и роковые ошибки. Clio-science: Проблемы истории и междисциплинарного синтеза: Сборник научных трудов. Выпуск VII. M., МПГУ: 204-258.

13. Цветков В.Ж. 2017. Определения «идеологической диверсии» и методика контрпропаганды в разработках отечественных спецслужб в конце 1970-х - начале 1980-х гг. Исторические чтения на Лубянке. ХХ лет. М., Наука. 265-274.

14. Широнин В.С. 2016. Агенты перестройки. Рассекреченное досье КГБ. М., Алгоритм, 241.

15. Шубин А.В. 2001. От «застоя» к реформам. СССР в 1978-1985 гг. М., РОССПЭН, 689.

16. Яковлев А.Н. 1964. Активизировать печать, радио, телевидение и кино как основные ударные идеологические силы партии. // ГА РФ. Ф. 10063. Оп. 1. Д. 59. Лл. 1-7.

17. Яковлев А.Н. 1969. Предложения о выработке принципиальной позиции в связи с 90-летием со дня рождения И.В. Сталина и поляризацией общественного мнения о его личности. // ГА РФ. Ф. 10063. Оп. 1. Д. 72. Лл. 1-5.

18. Яковлев Александр. 2009. Избранные интервью: 1992-2005 // Составитель А.А. Яковлев. М., Международный фонд «Демократия», 476.

19. Яковлев Александр. 2008. Перестройка: 1985-1991 // Составитель А.А. Яковлев. М., Международный фонд «Демократия», 867.

20. Pipes, Richard. 2015. Alexander Yakovlev: The Man Whose Ideas Delivered Russia from Communism. IL: NIU Press, 151.

\section{References}

1. Artemov A.V. 2017. Ideologiya obnovleniya v ritorike M.S. Gorbacheva kak bazovyj element obraza perestrojki (na primere podgotovki vystupleniya na fevral'skom Plenume CK KPSS 1988 g.) [Perestroika: 1985-1991. The ideology of renewal in the rhetoric of Mikhail Gorbachev as a basic element of the image of perestroika]. Vestnik Permskogo universiteta. Seriya: Istoriya. Vypusk 2 (37). 106-114.

2. Barsenkov A.S. 2001. Reformy Gorbacheva i sud'ba soyuznogo gosudarstva 1985-1991 [Gorbachev's reforms and the fate of the Union state 1985-1991]. M., Izdatel'stvo Moskovskogo universiteta. 364.

3. Bobkov F.D. 2011. Kak gotovili predatelej. Nachal'nik politicheskoj kontrrazvedki svidetel'stvuet [How traitors were trained. The head of political counterintelligence testifies]. M.: Eksmo, 240.

4. Vilkov A.A., Pivovarov V.A. 2016. Propagandistskij faktor dezorientacii i raskola sovetskogo obshchestva i raspada SSSR [Propaganda factor of disorientation and split of the Soviet society and the collapse of the USSR]. Izvestiya Saratovskogo universiteta. Seriya: Sociologiya, politologiya. Tom 16, vypusk $4.432-438$.

5. Volkogonov D.A. 1983. Psihologicheskaya voina: podryvnye deistvia v oblasti obchestvennogo soznania [Psychological warfare: Subversive actions in the field of public consciousness]. M., Voenizdat, 283.

6. Kaz'mina M.V. Kaz'min V.N. 2017. Otechestvennaya istoriografiya 1970-h godov - nachala XXI veka ob idejno-politicheskoj zhizni Rossii 1971-1991 godov [Russian historiography of the 1970s the beginning of the XXI century about the ideological and political life of Russia in 1971-1991]. Vestnik Kemerovskogo gosudarstvennogo universiteta. № 2. 50-57.

7. Kryuchkov V.A. 2003. Lichnoe delo [Private affair]. M.: Eksmo. 480.

8. Ligachev E.K. 2011. Kto predal SSSR? [Who betrayed the USSR?]. M.: Algoritm-Eksmo. 285.

9. Logvenkov I.S. 2017. Demontazh SSSR: istoriografiya prichin, uslovij i faktorov [Dismantling the USSR: historiography of causes, conditions and factors]. Vestnik Moskovskogo universiteta. Seriya 21. Upravlenie (gosudarstvo i obshchestvo), № 4. 129-145. 
10. Medvedev R.A. 2010. Sovetskij Soyuz. Poslednie gody zhizni [Soviet Union. The last years of his life]. M.: AST. 637.

11. Minutko I.A. 2010. Providec. [Seer]. M.: Nezavisimoe izdatel'stvo «PIK», Rossijskaya politicheskaya enciklopediya, 560.

12. Tsvetkov V.G. 2016. Aktual'nost' opyta ideologicheskoj raboty v period podgotovki i nachala «perestrojki» v SSSR: nerealizovannye vozmozhnosti i rokovye oshibki [Relevance of the experience of ideological work in the period of preparation and beginning of «perestroika» in the USSR: unrealized opportunities and fatal mistakes]. M., MPGU, 204-258.

13. Tsvetkov V.G. 2017. Opredeleniya «ideologicheskoj diversii» i metodika kontrpropagandy v razrabotkah otechestvennyh specsluzhb v konce 1970-h - nachale 1980-h gg. [Definitions of «ideological sabotage» and methods of counter-propaganda in the development of domestic special services in the late 1970s and early 1980s]. M., Istoricheskie chtenia na Lubyanke. 265-274.

14. Shironin V.S. Agenty perestrojki. Rassekrechennoe dos'e KGB [Perestroika Agents. Declassified KGB dossier]. M.: Algoritm. 2016. 241.

15. Shubin A.V. Ot «zastoya»k reformam. SSSR v 1978-1985 gg. [From «stagnation» to reforms. USSR in 1978-1985]. M.: ROSSPEN, 2001. 689 s. (in Russian).

16. Yakovlev A.N. 1964. Aktivizirovat' pechat', radio, televidenie i kino kak osnovnye udarnye ideologicheskie sily partii. $1964 \mathrm{~g}$. [To active press, TV and radio as importance ideological party forces]. GA RF. F. 10063. Op. 1. D. 59. Ll. 1-7.

17. Yakovlev A.N. 1969. Predlozheniya A.N. Yakovleva o vyrabotke principial'noj pozicii v svyazi s 90-letiem so dnya rozhdeniya I.V. Stalina i polyarizaciej obshchestvennogo mneniya o ego lichnosti. Oktyabr' 1969 g. [Proposals of A.N. Yakovlev on the development of a principled position in connection with the 90th anniversary of the birth of I.V. Stalin and the polarization of public opinion about his personality. October 1969] // GA RF. F. 10063. Op. 1. D. 72. Ll. 1-5.

18. Yakovlev Aleksandr. 2009. Izbrannye interv'yu: 1992-2005 [Interview. 1992-2005]. Sostavitel' A.A. Yakovlev. M., Mezhdunarodnyj fond «Demokratiya», 476.

19. Yakovlev Aleksandr. 2008. Perestrojka: 1985-1991 [Perestroyka. 1985-1991]. Sostavitel A.A. Yakovlev. M.: Mezhdunarodnyj fond «Demokratiya», 867.

20. Pipes, Richard. 2015. Alexander Yakovlev: The Man Whose Ideas Delivered Russia from Communism. IL: NIU Press, 151.

\section{Ссылка для цитирования статьи Link for article citation}

Сивов А.Н. 2020. Особенности идеологической позиции «архитектора перестройки», первого заместителя заведующего отделом пропаганды ЦК КПСС А.Н. Яковлева в 1960-1970-е годы. Via in tempore. История. Политология, 47 (2): 378-386. DOI 10.18413/2687-0967-2020-47-2-378-386.

Sivov A.N. 2020. Features of the ideological position of the «architect of perestroika», first deputy head of the propaganda department of the CPSU Central Committee A.N. Yakovlev in the 1960s and 1970s. Via in tempore. History and political science, 47 (2): 378-386 (in Russian). DOI 10.18413/2687-0967-2020-47-2-378-386. 